\title{
Female sex, high soluble CD163, and low HDL-cholesterol were associated with high galectin-3 binding protein in type 1 diabetes
}

\author{
Eva Olga Melin ${ }^{1,2^{*}}$, Jonatan Dereke $e^{1}$ and Magnus Hillman ${ }^{1}$
}

\begin{abstract}
Background: Galectin-3 binding protein (Gal3BP), sCD163, galectin-3, and depression have been linked to cardiovascular disease and mortality. In patients with type 1 diabetes, female sex has also been linked to cardiovascular disease and mortality. The aim was to explore whether female sex, sCD163, galectin-3, and depression were associated with Gal3BP in patients with type 1 diabetes. We adjusted for metabolic variables, creatinine, smoking, physical inactivity, and cardiovascular disease.

Methods: Cross-sectional design. Patients with type 1 diabetes $(n=285$, women 44\%, age 18-59 years, diabetes duration 1-55 years) were consecutively recruited from one diabetes outpatient clinic. Blood samples, anthropometrics, and blood pressure were collected, supplemented with data from electronic medical records. High Gal3BP was defined as $\geq 3.3 \mathrm{mg} / \mathrm{l}$ ( $\geq 80$ th percentile). Depression was assessed by a self-report instrument. Linear and logistic regression models were elaborated for the associations and calibrated and validated for goodness of fit with the data variables.

Results: Median $\left(q_{1}, q_{3}\right)$ Gal3BP was $2.3(1.8,3.1) \mathrm{mg} / \mathrm{l}$. The prevalence of high Gal3BP for women was 30\% and $14 \%$ for men $(p=0.001$ ). Female sex (adjusted odds ratio (AOR) 3.0), sCD163 (per $\mu \mathrm{g} / \mathrm{l}$ ) (AOR 6.6), and total cholesterol (per mmol/l) (AOR 1.6) were positively associated with high Gal3BP, and HDL-cholesterol (per mmol/l) (AOR 0.2) was negatively associated with high Gal3BP.

Conclusions: High Gal3BP levels were associated with female sex, increasing sCD163 and total cholesterol levels, and decreasing HDL-cholesterol levels in patients with type 1 diabetes. The prevalence of high Gal3BP was more than twice as high in the women as in the men.
\end{abstract}

Keywords: Biomarkers, Depression, Galectin-3, Galectin-3 binding protein , HDL-cholesterol, Inflammation, Sex differences, sCD163, Type 1 diabetes

\section{Background}

Type 1 diabetes (T1D) is an autoimmune disease, characterised by insulin deficiency due to pancreatic $\beta$-cell loss leading to hyperglycaemia [1]. T1D is associated with increased risk for myocardial infarction, heart failure, and ischemic stroke [2]. There are gender differences with greatly increased coronary artery calcification

\footnotetext{
* Correspondence: eva.melin@kronoberg.se; eva.o.melin@gmail.com

1 Diabetes Research Laboratory, Lund University, Lund, Sweden

2Department of Research and Development, Region Kronoberg, Box 1223 SE-351 12 Växjö, Sweden
}

(c) The Author(s). 2019 Open Access This article is distributed under the terms of the Creative Commons Attribution 4.0 International License (http://creativecommons.org/licenses/by/4.0/), which permits unrestricted use, distribution, and reproduction in any medium, provided you give appropriate credit to the original author(s) and the source, provide a link to the Creative Commons license, and indicate if changes were made. The Creative Commons Public Domain Dedication waiver (http://creativecommons.org/publicdomain/zero/1.0/) applies to the data made available in this article, unless otherwise stated. with T1D also have a significantly greater excess risk of death from cardiovascular (CV) disease across all age groups compared to men with T1D [4].

Macrophages are major components of atherosclerotic plaques, and classically activated macrophages (M1) contribute to plaque instability [5]. Galectin-3 binding protein (Gal3BP), also known as Mac-2 binding protein or $90 \mathrm{~K}$, is a macrophage scavenger receptor [6]. Gal3BP binds to several galectins, including galectin-3 [7]. Gal3BP is a marker of macrophage inflammation [5] and 
induces a number of pro-inflammatory cytokines in human macrophages [8]. Increased plasma levels of Gal3BP have been associated with several metabolic variables and with $\mathrm{CV}$ and all-cause mortality [8].

Galectin-3 is a beta-galactoside-binding lectin, also known as known as Mac-2 [6, 7]. Galectin-3 is involved in several inflammatory processes [9] and marks activated macrophages in failure-prone hypertrophied hearts, predicting and contributing to cardiac dysfunction [10, 11]. Galectin-3 has been associated with coronary artery disease $(\mathrm{CAD})$ and $\mathrm{CV}$ death in high-risk patients referred for coronary angiography [12]. It has also been linked to adverse CV outcomes in type 2 diabetes (T2D) independent of traditional risk factors [13].

CD163 is a macrophage and monocyte-expressed scavenger receptor [14]. As a result of ectodomain shedding, the extracellular portion of CD163 circulates in blood as a soluble protein (sCD163) [15]. sCD163 levels increase during inflammation and macrophage activation [15]. Increased sCD163 levels have been linked to acute coronary syndrome [16]. Increased sCD163 levels have also been linked to variables included in the metabolic syndrome and to T2D [15, 17-19]. Gal3BP and sCD163 were significantly correlated with each other, and both were associated with increased atherosclerotic lesions and lower carotid distensibility in the setting of HIV and hepatitis $C$ virus infections [5]. We previously found that serum levels of galectin-3 were linked to circulatory sCD163 in these T1D patients [20].

Depression has been linked to immunological changes [21] and is associated with increased CV and all-cause mortality [22]. We have previously found that depression in T1D patients was associated with high galectin-3 serum levels [23], inadequate glycemic control [24], high midnight salivary cortisol secretion [25], and low HDLcholesterol levels in T1D patients [26].

Weight gain and abdominal obesity in T1D are associated with CV risk factors and atherosclerosis [27, 28]. We previously demonstrated that the prevalence of abdominal obesity was 3.6 times higher in women compared to men with T1D $[28,29]$.

We hypothesised that female sex, galectin-3, sCD163, and depression, previously linked to CVD and mortality, were associated with Gal3BP in a setting of patients with T1D. We adjusted for metabolic variables, creatinine, smoking, and physical inactivity.

\section{Methods}

\section{Participants and study design}

This study has a cross-sectional design and included 285 patients with T1D. Inclusion criteria were T1D with $\geq 1$ year duration, in patients 18-59 years of age. Exclusion criteria were pregnancy; severe somatic and psychiatric disorders such as cancer, hepatic failure, and end-stage renal disease (ESRD); severe autoimmune disorders such as SLE, psychotic disorders, bipolar disorder; severe personality disorders; severe substance abuse; cognitive deficiency (due to stroke, dementia or mental retardation); and inadequate knowledge of Swedish. For inclusion and exclusion criteria, as well as missing values, see Fig. 1.The patients who attend the clinic every 6 months for regular follow-up visits were consecutively recruited by diabetes specialist physicians or diabetes specialist nurses during a 9-month period, $03 / 25 / 2009$ to $12 / 28 / 2009$, from one hospital diabetes outpatient clinic in Kronoberg County, Sweden. The catchment population was 125,000 . Blood and saliva samples, anthropometrics, and blood pressure were collected, supplemented with data from medical records. A questionnaire was used to assess self-reported depression.

\section{Biochemical analyses}

Plasma levels of galectin-3BP, galectin-3, and sCD163 were measured using commercially available DuoSet enzyme-linked immune-sorbent assay (ELISA) kits (R\&D Systems, Minneapolis, Minnesota, USA) and optimised for human plasma [30]. The analyses were run according to the manufacturer's instructions. The samples were diluted 1:4000, 1:2, and 1:200 for the Gal3BP, galectin-3 and sCD163 analyses, respectively. The intra-assay coefficients were $3.9 \%, 4.3 \%$, and $2 \%$ for the Gal3BP, galectin-3, and sCD163 analyses, respectively. All samples were run as duplicates. Gal3BP was dichotomised at the 80th percentile.

HbA1c (mmol/mol, \%) and serum lipids $(\mathrm{mmol} / \mathrm{l})$ were collected after an overnight fast and analysed with an Olympus AU clinical chemistry analyser with high specificity (Olympus $\mathrm{AU}^{\circ}$, Tokyo, Japan) [31]. The intracoefficients of variation were $\mathrm{HbA} 1 \mathrm{c}<1.2 \%$; total cholesterol < 2.1\%; HDL-cholesterol < 3.0\%; LDL-cholesterol < $2.6 \%$; and triglycerides $<2.2 \%$. Serum-lipids were measured directly [32].

\section{Anthropometrics and blood pressure}

Waist circumference (WC), weight, length, and blood pressure were measured according to standard procedures by a nurse. Abdominal obesity was defined as $W C \geq 1.02 \mathrm{~m}$ for men and as $\mathrm{WC} \geq 0.88 \mathrm{~m}$ for women. General obesity was defined as BMI $\geq 30 \mathrm{~kg} / \mathrm{m}^{2}$ for both sexes [33].

\section{Episodes of hypoglycemia}

A severe episode of hypoglycemia was defined as needing help from another person. Episodes during the last 6 months prior to recruitment were registered.

\section{Smoking and physical inactivity}

Smokers were defined as having smoked any amount of tobacco during the last year. Physical inactivity was 


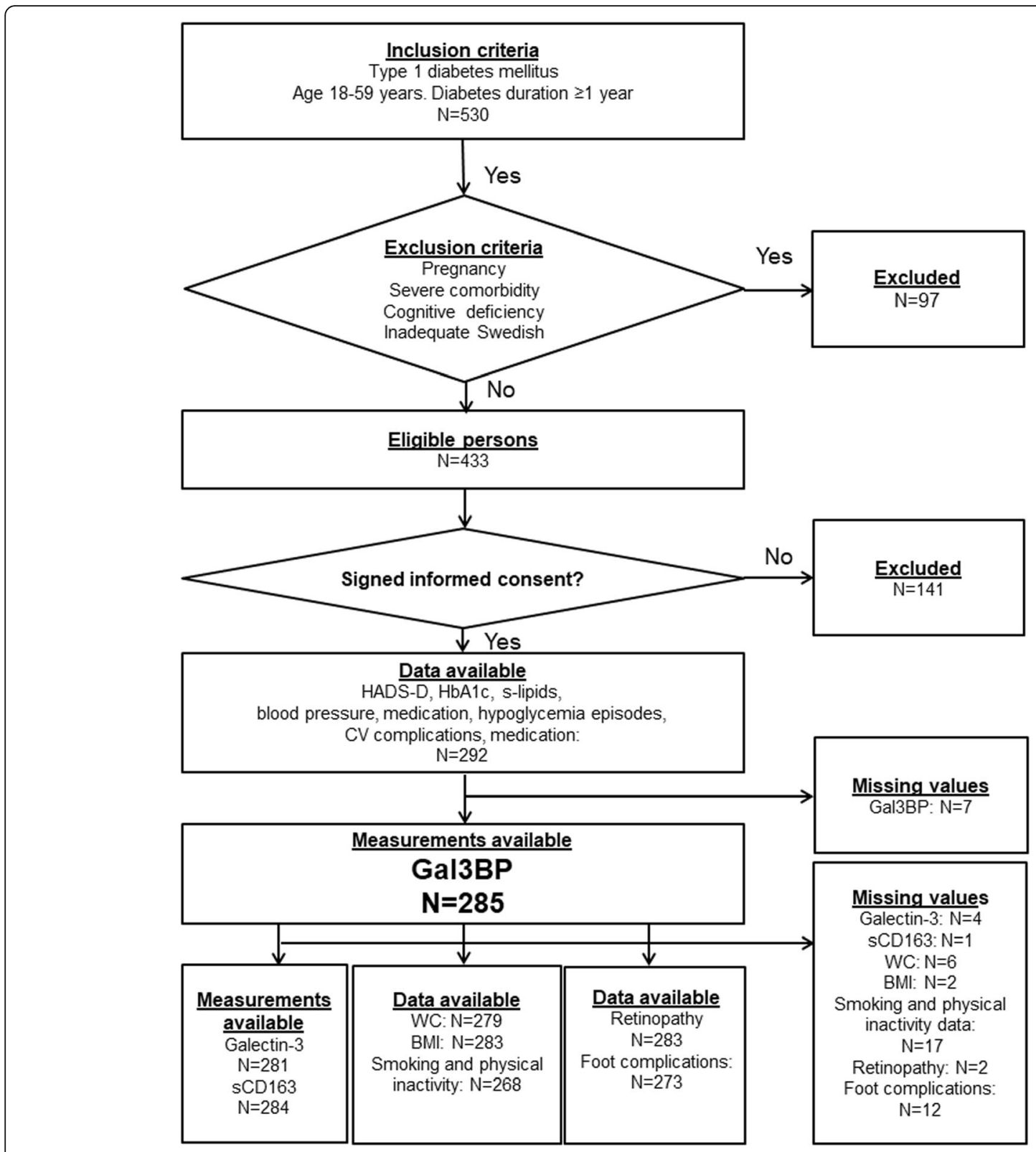

Fig. 1 Flow chart showing inclusion and exclusion criteria and missing values

defined as moderate activities, such as 30 min of walking, less than once a week.

\section{Cardiovascular complications (CV)}

$\mathrm{CV}$ complications were defined as ischemic heart disease, cardiac failure, stroke, or transient ischemic attack (TIA).

\section{Diabetic retinopathy (DR)}

DR was defined as non-proliferative or proliferative retinopathy with microangiopathy changes as viewed by fundus photography through a dilated pupil.

\section{Foot complications}

These were defined as neuropathy, angiopathy, earlier or present diabetes foot ulcer, foot infection, foot deformity, arthropathy, or amputation of the lower limb.

\section{Self-reported depression}

Depression was defined as Hospital Anxiety and Depression Scale-Depression subscale (HADS-D) $\geq 8$ points [34].

\section{Medication}

Patients used either multiple daily insulin injections (MDII) or continuous subcutaneous insulin infusion (CSII). 
Antidepressants (AD) were SSRIs (ATC codes N06AB04 and N06AB10); SNRIs (ATC code N06AX16); combined serotonin and norepinephrine reuptake inhibitors (ATC code N06AX21); tricyclic antidepressants (ATC code N06AA04); and/or tetracyclic antidepressants (ATC code N06AX11). The use of antidepressants was dichotomised into users and non-users of antidepressants.

Lipid lowering drugs (LLDs) were defined equal to HMG CoA-reductase inhibitors (statins), ATC-code C10AA. Indications for LLD were TC $>4.5 \mathrm{mmol} / \mathrm{l}(>1.74 \mathrm{mg} / \mathrm{dl})$ and/ or LDL-cholesterol $>2.5 \mathrm{mmol} / \mathrm{l}(>97 \mathrm{mg} / \mathrm{dl})$ according to the Swedish national guidelines in 2009. The use of LLD was dichotomised into users and non-users of LLD [35].

Antihypertensive drugs (AHD) included calcium antagonists with ATC codes C08CA01-02; angiotensin-converting enzyme (ACE) inhibitors with ATC codes C09AA-BA; angiotensin II antagonists, ATC codes C09CA-DA; diuretics, ATC codes C03AA03 or C03CA01; and/or selective beta-adrenoreceptor antagonists, ATC code C07AB. Indications for AHD were systolic blood pressure $>130 \mathrm{mmHg}$ and/or diastolic blood pressure $>80 \mathrm{mmHg}$ according to the Swedish national guidelines in 2009 [35]. The use of AHD was dichotomised into users and non-users of AHD.

\section{Statistical analysis}

Analysis of data distribution using histograms revealed that Gal3BP, galectin-3, sCD163, and triglycerides were not normally distributed. Data were presented as median values (quartile $(\mathrm{q})_{1}, \mathrm{q}_{3}$; range), and analyses were performed with Mann-Whitney $U$ test. Fisher's Exact Test (two-tailed) was used to analyse categorical data. Logtransformations were performed for Gal3BP, sCD163, and galectin-3. Linear regression analyses were performed between log-transformed galectin-3 and logtransformed Gal3BP; between log-transformed sCD163 and log-transformed Gal3BP; and between age and logtransformed Gal3BP.

Crude odds ratios (CORs) for the associations with high Gal3BP ( $\geq 3.3 \mathrm{mg} / \mathrm{l}$ ) were calculated. Variables with $p \leq 0.10$ for the CORs, and age independent of $p$ value, were entered into multiple logistic regression analyses (Backward: Wald) with Gal3BP $\geq 3.3 \mathrm{mg} / \mathrm{l}$ as dependent variable for all, women and men. The Hosmer-Lemeshow test for goodness of fit and Nagelkerke $R^{2}$ were used to evaluate each multiple logistic regression analysis model. Confidence intervals (CIs) of $95 \%$ were used. $p<0.05$ was considered statistically significant. SPSS ${ }^{\circ}$ version 25 (IBM, Chicago, Illinois, USA) was used.

\section{Results}

In this study, 285 patients with T1D (56\% men, age 1859 years, diabetes duration 1-55 years) were included. The patients used either MDII (91\%) or CSII (9\%).
In Table 1, baseline characteristics, laboratory test results, and sex differences between the 124 women and 161 men are presented. The 124 women had higher median Gal3BP than the 161 men $(p<0.001)$.

Log-transformed sCD163 and log-transformed Gal3BP were associated for all patients $\left(R^{2}=0.020\right.$, standardised beta coefficient $0.143, p=0.016)$, and for men $\left(R^{2}=\right.$ 0.029 , standardised beta coefficient $0.170, p=0.031$ ), but not for women $\left(R^{2}=0.016\right.$, standardised beta coefficient $0.128, p=0.16$ ). Log-transformed galectin-3 and logtransformed Gal3BP were not associated (all patients: $p=0.20$; women: $p=0.44$; men: $p=0.18$ ). Age and logtransformed Gal3BP were not associated (all patients: $p=0.49$; women: $p=0.51$; men: $p=0.82$ ).

In Table 2, comparisons are performed between patients with low and high Gal3BP for all and for each sex. High Gal3BP was defined as $\geq 3.3 \mathrm{mg} / \mathrm{l}$, corresponding to the 80th percentile.

The prevalence of high Gal3BP was 2.1 times higher in the women than in the men (30\% versus $14 \%)(p=$ 0.001). Comparisons between 59 patients with high Gal3BP and 226 patients with low Gal3BP showed that the patients with high Gal3BP had higher medians of HbA1c $(p=0.004)$ and triglycerides $(p=0.001)$ and higher prevalence of general obesity $(p=0.002)$. The 37 women with high Gal3BP levels compared to the 87 women with low Gal3BP levels had higher median HbA1c $(p=0.013)$ and higher prevalence of antidepressant use $(p=0.041)$. The 22 men with high Gal3BP levels compared to the 139 men with low Gal3BP levels had higher medians of galectin-3 $(p=0.035)$, triglycerides $(p<0.001)$, and LDL-cholesterol $(p=0.036)$; higher prevalence of general obesity $(p=0.002)$; and lower median HDL-cholesterol $(p=0.024)$.

In Table 3, variables associated with high Gal3BP are presented for all and for each sex. In all patients, female sex (AOR 3.0), sCD163 (per mg/l) (AOR 6.6), and total cholesterol (per mmol/l) (AOR 1.6) were positively associated, and HDL-cholesterol (per mmol/l) (AOR 0.2) was negatively associated with high Gal3BP. In the women, $\mathrm{HbA1c}$ (per $\mathrm{mmol} / \mathrm{mol}$ ) (AOR 1.03) was associated with high Gal3BP. In the men, sCD163 (per mg/l) (AOR 11.2), total cholesterol (per mmol/l) (AOR 2.3), and general obesity (AOR 7.9) were positively associated, and HDL-cholesterol (per mmol/l) (AOR 0.2) was negatively associated with high Gal3BP.

\section{Discussion}

In this study of 285 patients with T1D, high Gal3BP levels $(\geq 3.3 \mathrm{mg} / \mathrm{l})$ were associated with female sex, increasing sCD163 and total cholesterol levels, and decreasing HDL-cholesterol levels. The prevalence of high Gal3BP was more than twice as high in the women as in the men. In the women, high Gal3BP levels were 
Table 1 Baseline characteristics, laboratory results, and sex differences between 124 women and 161 men with T1D

\begin{tabular}{|c|c|c|c|c|}
\hline \multirow[t]{2}{*}{ Variables } & \multirow{2}{*}{$\begin{array}{l}\text { All patients } \\
n=285\end{array}$} & \multirow{2}{*}{$\begin{array}{l}\text { Women } \\
n=124\end{array}$} & \multirow{2}{*}{$\begin{array}{l}\text { Men } \\
n=161\end{array}$} & \multirow[b]{2}{*}{$p$ value } \\
\hline & & & & \\
\hline Age (years) & $42(32,51 ; 18-59)$ & $41(30,50)$ & $43(32,52)$ & 0.10 \\
\hline Diabetes duration (years) & $20(11,30 ; 1-55)$ & $19(11,29)$ & $21(11,32)$ & 0.27 \\
\hline Gal3BP b $(m g / l)$ & $2.3(1.8,3.1 ; 0.8-8.9)$ & $2.6(1.9,3.6)$ & $2.1(1.6,2.8)$ & $<0.001$ \\
\hline $\mathrm{sCD} 163(\mathrm{mg} / \mathrm{ll})^{\mathrm{c}}$ & $0.4(0.3,0.5 ; 0.2-1.9)$ & $0.4(0.3,0.6)$ & $0.4(0.3,0.5)$ & 0.78 \\
\hline Galectin-3 ( $\mu \mathrm{g} / \mathrm{l})$ & $0.9(0.6-1.7 ; 0.001-100)$ & $0.9(0.5,1.4)$ & $0.9(0.6,2.0)$ & 0.15 \\
\hline \multicolumn{5}{|l|}{$\mathrm{HbA1c}$} \\
\hline $\mathrm{mmol} / \mathrm{mol}$ & $63(54,71 ; 25-110)$ & $64(54,72)$ & $63(54,69)$ & \multirow[t]{2}{*}{0.33} \\
\hline$\%$ & $7.9(7.1,8.6 ; 4.4-12.2)$ & $8.0(7.1,8.7)$ & $7.9(7.1,8.5)$ & \\
\hline Total cholesterol (mmol/l) & $4.6(4.1,5.1 ; 2.1-10.9)$ & $4.6(4.1,5.4)$ & $4.5(4.0,5.1)$ & 0.13 \\
\hline Triglycerides (mmol/l) & $0.9(0.7,1.3 ; 0.1-5.9)$ & $0.8(0.6,1.3)$ & $0.9(0.7,1.3)$ & 0.32 \\
\hline LDL-cholesterol (mmol/l) & $2.8(2.4,3.3 ; 0.6-8.3)$ & $2.8(2.4,3.4)$ & $2.8(2.4,3.3)$ & 0.79 \\
\hline HDL-cholesterol (mmol/l) & $1.5(1.3,1.8 ; 0.3-2.7)$ & $1.6(1.4,1.9)$ & $1.4(1.2,1.7)$ & 0.003 \\
\hline Creatinine $(\mu \mathrm{mol} / \mathrm{l})^{d}$ & $70(62,182 ; 28-182)$ & $62(54,70)$ & $74(68,82)$ & $<0.001$ \\
\hline Abdominal obesity ${ }^{e}$ & $47(17)$ & $34(28)$ & $13(8)$ & $<0.001^{f}$ \\
\hline General obesity ${ }^{9}$ & $34(12)$ & $22(18)$ & $12(8)$ & $0.009^{f}$ \\
\hline Systolic BP (mmHg) & $20(110,130 ; 90-160)$ & $120(110,130)$ & $125(120,130)$ & $<0.001$ \\
\hline Diastolic BP (mmHg) & $70(70,76 ; 55-100)$ & $70(65,75)$ & $70(70,80)$ & $<0.001$ \\
\hline Smoking ${ }^{h}$ & $27(10)$ & $10(9)$ & $17(11)$ & $0.55^{f}$ \\
\hline Physical inactivity ${ }^{i}$ & $29(11)$ & $12(10)$ & $17(11)$ & $>0.99^{f}$ \\
\hline Depression & $30(10)$ & $14(11)$ & $16(10)$ & $0.85^{f}$ \\
\hline Cardiovascular complications & $10(4)$ & $4(3)$ & $6(4)$ & $>0.99^{f}$ \\
\hline Diabetes retinopathy ${ }^{j}$ & $205(72)$ & $88(72)$ & $117(73)$ & $0.79^{f}$ \\
\hline Foot complications ${ }^{k}$ & $47(17)$ & $13(11)$ & $34(22)$ & $0.023^{f}$ \\
\hline Antidepressants & $23(8)$ & $12(10)$ & $11(7)$ & $0.39^{f}$ \\
\hline Antihypertensive drugs & $96(34)$ & $35(28)$ & $61(38)$ & $0.10^{f}$ \\
\hline Lipid lowering drugs & $133(47)$ & $55(44)$ & $78(48)$ & $0.55^{f}$ \\
\hline
\end{tabular}

${ }^{\mathrm{a}}$ Mann-Whitney $U$ test unless otherwise indicated. ${ }^{\mathrm{b}}$ galectin-3 binding protein. ${ }^{\mathrm{f}}$ Fisher's Exact test. Missing values (N) (all/women/men): ${ }^{\mathrm{c}} 1 / 1 / 0 ;{ }^{\mathrm{d}} 13 / 6 / 7 ;{ }^{\mathrm{e}} 6 / 3 / 3$; ${ }^{g} 2 / 2 / 0 ;{ }^{h, i} 17 / 9 / 8 ;{ }^{j} 2 / 1 / 1 ;{ }^{k} 12 / 7 / 5$

associated with HbA1c. In the men, high Gal3BP levels were associated with increasing sCD163 and total cholesterol levels, decreasing HDL-cholesterol levels, and general obesity. High Gal3BP was neither associated with galectin-3 nor depression.

The first strength of this study is that the population of patients with T1D was well-defined. Patients with severe somatic or psychiatric comorbidities and/or substance abuse were excluded, as well as pregnant women. Of particular importance are that no patients with ESRD were included as ESRD is accompanied by immune dysfunction [36] and that no patients with a severe autoimmune disorder such as SLE, liver cirrhosis, or cancer were included as Gal3BP is involved in several of these conditions [8, 37, 38]. Second, we have included relevant variables as disturbances of sCD163, galectin-3, and metabolic variables previously have been linked to CVD $[4,5,8,10,11,13,16,28,32,33,39]$. Depression, smoking, and physical inactivity were also included due to their previously demonstrated impact on CVD and mortality [22, 40, 41]. Third, precise ELISA techniques were used. The commercial ELISA assay showed low intra-assay coefficients of variation for Gal3BP, sCD163, and galectin-3.

One limitation was that the number of patients with CV complications was low, so we could neither confirm nor exclude any association between Gal3BP and $\mathrm{CV}$ complications. Other limitations were that we have not measured any sex hormones and there were no data available regarding menopause. However, we did not find any correlation between Gal3BP and age, so there was no indication that menopause was of particular importance for determining the Gal3BP levels.

To our knowledge, we are the first to explore the associations between Gal3BP and sex, galectin-3, sCD163, 
Table 2 Comparisons between low and high Gal3BP presented for all 285 patients and for each sex

\begin{tabular}{|c|c|c|c|c|c|c|c|c|c|}
\hline \multirow[t]{3}{*}{ Variables } & \multicolumn{9}{|c|}{ High Gal3BP (mg/l) ( $\geq 3.3$ mg/l, $\geq 80$ th percentile) } \\
\hline & \multicolumn{3}{|c|}{ All patients $(n=285)$} & \multicolumn{3}{|c|}{ Women $(n=124)$} & \multicolumn{3}{|l|}{ Men $(n=161)$} \\
\hline & No & Yes & $\overline{p \text { value }^{a}}$ & No & Yes & $\overline{p \text { value }^{a}}$ & No & Yes & $\overline{p \text { value }}{ }^{a}$ \\
\hline N & $226(79)$ & $59(21)$ & & $87(70)$ & $37(30)$ & & $139(86)$ & $22(14)$ & \\
\hline \multicolumn{10}{|l|}{ Gender } \\
\hline Women & 87 (39) & $37(63)$ & $0.001^{b}$ & - & - & - & - & - & - \\
\hline Men & $139(62)$ & $22(37)$ & & - & - & - & - & - & - \\
\hline Age & $42(32,51)$ & $41(29,50)$ & 0.49 & $42(31,51)$ & $40(30,48)$ & 0.63 & $43(32,51)$ & $4625,55)$ & 0.98 \\
\hline Diabetes duration & $21(11,31)$ & $18(11,27)$ & 0.093 & $19(10,29)$ & $19(13,28)$ & $>0.99$ & $21(13,33)$ & $16(6,26)$ & 0.032 \\
\hline sCD163 (mg/l) & $0.4(0.3,0.5)$ & $0.5(0.3,0.6)$ & 0.088 & $0.4(0.3,0.5)$ & $0.5(0.3,0.6)$ & 0.15 & $0.4(0.3 .0 .5)$ & $0.5(0.3-0.6)$ & 0.26 \\
\hline Galectin-3 ( $\mu \mathrm{g} / \mathrm{l})$ & $0.9(0.6,1.6)$ & $1.2(0.7,2.1)$ & 0.056 & $0.8(0.5,1.4)$ & $1.1(0.5,1.7)$ & 0.24 & $0.9(0.6,1.9)$ & $1.7(0.8,2.6)$ & 0.035 \\
\hline \multicolumn{10}{|l|}{$\mathrm{HbA} 1 \mathrm{c}$} \\
\hline $\mathrm{mmol} / \mathrm{mol}$ & $61(54,69)$ & $68(58,79)$ & 0.004 & $63(53,71)$ & $71(59,82)$ & 0.013 & $61(54,68)$ & $65(55,76)$ & 0.20 \\
\hline$\%$ & $7.8(7.1-8.4)$ & $8.4(7.5-9.4)$ & & $7.9(7.0,8.6)$ & $8.6(7.5,9.6)$ & & $7.8(7.1,8.4)$ & $8.1(7.2,9.1)$ & \\
\hline TC (mmol/l) & $4.5(4.1,5.1)$ & $4.7(4.1,5.3)$ & 0.20 & $4.6(4.1,5.3)$ & $4.7(4.9,5.4)$ & 0.90 & $4.4(4.0,5.0)$ & $4.8(4.2,5.1)$ & 0.14 \\
\hline Triglycerides (mmol/l) & $0.9(0.6,1.1)$ & $1.0(0.8,1.6)$ & 0.001 & $0.8(0.6,1.1)$ & $1.0(0.7,1.5)$ & 0.065 & $0.9(0.7,1.2)$ & $1.2(1.0,1.8)$ & $<0.001$ \\
\hline LDL-cholesterol (mmol/l) & $2.8(2.4,3.2)$ & $3.0(2.4,3.6)$ & 0.12 & $2.8(2.4,3.3)$ & $2.9(2.2,3.6)$ & 0.82 & $2.8(2.4,3.2)$ & $3.2(2.6,3.6)$ & 0.036 \\
\hline HDL-cholesterol (mmol/l) & $1.5(1.3,1.8)$ & $1.4(1.1,1.7)$ & 0.053 & $1.6(1.4,1.9)$ & $1.5(1.2,1.8)$ & 0.17 & $1.5(1.2,1.8)$ & $1.3(1.1,1.5)$ & 0.024 \\
\hline Creatine $(\mu \mathrm{mol} / \mathrm{l})$ & $70(63-80)$ & $66(53-76)$ & 0.005 & $64(56,70)$ & $61(52,69)$ & 0.17 & $74(68,82)$ & $72(66,80)$ & 0.30 \\
\hline Abdominal obesity & $37(16)$ & $10(18)$ & $0.84^{b}$ & $25(29)$ & $9(26)$ & $>0.99^{b}$ & $12(9)$ & $1(5)$ & $>0.99^{b}$ \\
\hline General obesity & $20(9)$ & $14(25)$ & $0.002^{b}$ & $14(16)$ & $8(23)$ & $0.44^{b}$ & $6(4)$ & $6(27)$ & $0.002^{b}$ \\
\hline Systolic BP (mmHg) & $120(115,130)$ & $120(110,130)$ & 0.37 & $120(110,130)$ & $115(110,130)$ & 0.57 & $125(120,130)$ & $128(110,136)$ & 0.69 \\
\hline Diastolic BP (mmHg) & $70(70,76)$ & $70(65,75)$ & 0.48 & $70(65,75)$ & $70(62,70)$ & 0.27 & $70(70,80)$ & $75(70,80)$ & 0.19 \\
\hline Smoking & $21(10)$ & $6(11)$ & $0.80^{b}$ & $14(16)$ & $8(23)$ & $0.44^{b}$ & $14(10)$ & $3(15)$ & $0.47^{b}$ \\
\hline Physical inactivity & $19(9)$ & $10(18)$ & $0.085^{b}$ & $6(7)$ & $6(18)$ & $0.18^{b}$ & $13(10)$ & $4(19)$ & $0.26^{b}$ \\
\hline Depression & $21(9)$ & $9(15)$ & $0.23^{b}$ & $8(9)$ & $6(16)$ & $0.35^{b}$ & $8(9)$ & $6(16)$ & $0.35^{b}$ \\
\hline $\begin{array}{l}\text { Cardiovascular } \\
\text { complications }\end{array}$ & $6(3)$ & $4(7)$ & $0.22^{b}$ & $1(1)$ & $3(8)$ & $0.079^{b}$ & $5(4)$ & $1(4)$ & $0.59^{b}$ \\
\hline Diabetes retinopathy & $162(72)$ & $43(73)$ & $>0.99^{b}$ & $58(67)$ & $30(81)$ & $0.14^{b}$ & $104(75)$ & $13(59)$ & $0.12^{b}$ \\
\hline Foot complications & $36(16)$ & $11(20)$ & $0.55^{b}$ & $7(8)$ & $6(18)$ & $0.19^{b}$ & $29(22)$ & $5(23)$ & $>099^{b}$ \\
\hline Antidepressants & $16(7)$ & $7(12)$ & $0.28^{b}$ & $5(6)$ & $7(19)$ & $0.041^{b}$ & $11(8)$ & 0 & $0.36^{b}$ \\
\hline Antihypertensive drugs & 77 (34) & $19(32)$ & $0.88^{b}$ & $22(25)$ & $13(35)$ & $0.28^{b}$ & $55(40)$ & $6(27)$ & $0.35^{b}$ \\
\hline Lipid lowering drugs & $103(46)$ & $30(51)$ & $0.56^{b}$ & $36(41)$ & $19(51)$ & $0.33^{b}$ & $67(48)$ & $11(50)$ & $>0.99^{b}$ \\
\hline
\end{tabular}

${ }^{a}$ Mann-Whitney $U$ test unless otherwise indicated. ${ }^{\mathrm{b}}$ Fisher's Exact test

Abdominal obesity: women $p>0.99^{\mathrm{b}}$, men $p>0.99^{\mathrm{b}}$

General obesity: women $p=0.44^{\mathrm{b}}$, men $=0.002^{\mathrm{b}}$

depression, metabolic factors, and life style variables in patients with T1D. We have not found any previous study exploring Gal3BP levels in a population of T1D patients. One study states that Gal3BP levels are higher in patients with diabetes, but the authors did not distinguish between T1D and T2D [8].

To include sex in the analyses is of particular importance as CAC is greatly increased in women with T1D [3] and as women compared to men with T1D are at higher risk for $\mathrm{CV}$ death across all age groups [4]. To stratify for sex is also of utmost importance while performing autoimmune disease biomarker research [42]. Several sex differences of macrophage function, including activation levels, phagocytic capacity, and cytokine production, have been demonstrated [42]. Numerous cytokines released by macrophages are modulated by oestradiol, progesterone, or androgens [42]. We have not found any previous study exploring sex differences and the impact of sex hormones on galectin-3BP. We have only found one study that showed that Gal3BP levels could be modulated by hormones [43]. The explored hormones were TSH, insulin, and IGF-I, which all had modulation capacity [43].

We found an association between Gal3BP and sCD163 which is in accordance with previous research in the setting of $\mathrm{HIV}$ and $\mathrm{HCV}$ infections, where these two 
Table 3 Associations with high Gal3BP for all, women and men

\begin{tabular}{|c|c|c|c|c|c|c|c|c|}
\hline \multirow[t]{3}{*}{ Variables } & \multicolumn{8}{|c|}{ High galectin-3BP ( $\geq 3.3 \mathrm{mg} / \mathrm{l}, \geq 80$ th percentile) } \\
\hline & \multicolumn{4}{|c|}{ All patients } & \multicolumn{2}{|l|}{ Women } & \multicolumn{2}{|l|}{ Men } \\
\hline & COR & $p$ value & AOR & $p$ value $^{a}$ & $\mathrm{AOR}$ & $p$ value ${ }^{b}$ & $\overline{A O R}$ & $p$ value \\
\hline Sex (women) & $2.7(1.5-4.9)$ & 0.001 & $3.0(1.5-5.9)$ & 0.001 & - & - & - & - \\
\hline Age & $0.99(0.97-1.02)$ & 0.43 & $1.02(0.99-1.05)$ & 0.22 & $0.98(0.94-1.02)$ & 0.27 & $1.03(0.98-1.08)$ & 0.30 \\
\hline Diabetes duration & $0.98(0.95-1.00)$ & 0.076 & $0.98(0.95-1.00)$ & 0.11 & - & - & $0.96(0.92-1.01)$ & 0.14 \\
\hline sCD163 (mg/l) & $5.4(1.6-18.0)$ & 0.005 & $6.6(1.9-23.2)$ & 0.003 & $4.6(0.8-26.9)$ & 0.093 & $11.2(2.0-64.5))$ & 0.007 \\
\hline Galectin-3 ( $\mu \mathrm{g} / \mathrm{l})$ & $1.04(0.99-1.10)$ & 0.14 & - & - & - & - & - & - \\
\hline $\mathrm{HbA} 1 \mathrm{c} \mathrm{mmol} / \mathrm{mol}$ & $1.03(1.01-1.05)$ & 0.008 & $1.02(1.00-1.04)$ & 0.09 & $1.03(1.00-1.06)$ & 0.039 & - & - \\
\hline $\mathrm{TC}(\mathrm{mmol} / \mathrm{l})$ & $1.4(1.0-1.8)$ & 0.022 & $1.6(1.1-2.2)$ & 0.007 & - & - & $2.3(1.3-3.9)$ & 0.003 \\
\hline Triglycerides (mmol/l) & $1.5(1.1-2.1)$ & 0.014 & $0.9(0.5-1.5)$ & 0.58 & - & - & $0.7(0.4-1.5)$ & 0.41 \\
\hline LDL-cholesterol (mmol/l) & $1.5(1.1-2.2)$ & 0.017 & $0.6(0.1-3.5)$ & 0.53 & $1.1(0.6-1.8)$ & 0.76 & $0.4(0.03-6.6)$ & 0.56 \\
\hline HDL-cholesterol (mmol/l) & $0.45(0.2-1.0)$ & 0.059 & $0.2(0.1-0.7)$ & 0.010 & - & - & $0.2(0.02-0.9)$ & 0.040 \\
\hline Creatinine & $0.99(0.97-1.01)$ & 0.16 & - & - & - & - & - & - \\
\hline Abdominal obesity & $1.1(0.5-2.4)$ & 0.77 & - & - & - & - & - & - \\
\hline General obesity & $3.4(1.6-7.2)$ & 0.002 & $1.6(0.7-4.0)$ & 0.29 & - & - & $7.9(1.9-32.6)$ & 0.004 \\
\hline SBP & $0.99(0.96-1.01)$ & 0.26 & - & - & - & - & - & - \\
\hline DBP & $1.00(0.96-1.04)$ & 0.83 & - & - & - & - & - & - \\
\hline Smoking & $1.2(0.5-3.1)$ & 0.74 & - & - & - & - & - & - \\
\hline Physical inactivity & $2.3(1.0-5.2)$ & 0.053 & $1.8(0.7-4.8)$ & 0.22 & - & - & - & - \\
\hline Depression & $0.6(0.2-1.3)$ & 0.19 & - & - & - & - & - & - \\
\hline CV complications & $2.7(0.7-9.8)$ & 0.14 & - & - & $4.0(0.3-47.3)$ & 0.26 & - & - \\
\hline Diabetes retinopathy & $1.0(0.5-2.0)$ & 0.93 & - & - & - & - & - & - \\
\hline Foot complications & $1.3(0.6-2.7)$ & 0.54 & - & - & - & - & - & - \\
\hline$A D$ & $1.8(0.7-4.5)$ & 0.24 & - & - & $2.6(0.7-9.4)$ & 0.15 & - & - \\
\hline $\mathrm{AHD}$ & $0.9(0.5-1.7)$ & 0.79 & - & - & - & - & - & - \\
\hline LLD & $1.2(0.7-2.2)$ & 0.47 & - & - & - & - & - & - \\
\hline
\end{tabular}

biomarkers were correlated with each other [5]. In that study, both Gal3BP and sCD163 were associated with increased atherosclerotic lesions [5]. We did not find any association between galectin-3 and Gal3BP, which previously have been linked to each other in the context of cancer [7]. We have not found any studies exploring links between galectin-3 and Gal3BP in the context of T1D or CVD. In previous research, BMI and triglycerides were positively associated with Gal3BP, while HDL-cholesterol levels were negatively associated with Gal3BP [8]. Despite a much higher prevalence of obesity in the women than in the men, neither abdominal nor general obesity was associated with high Gal3BP in the women. General obesity was associated with high Gal3BP in the men only. The triglyceride levels were higher in patients with high Gal3BP, but there was no independent association between Gal3BP and triglycerides, which differs from previous research [8]. An association between lower HDL-cholesterol levels and high
Gal3BP levels was demonstrated in the men. The finding of an association between lower HDL-cholesterol and high Gal3BP levels is interesting as HDL-cholesterol protects against atherosclerosis by removing excess cholesterol from macrophages by the reverse cholesterol transport and additionally exerts anti-inflammatory actions [44]. Systemic and vascular inflammation have been proposed to convert HDL-cholesterol to a dysfunctional form that has impaired antiatherogenic effects, and even pro-inflammatory effects with increased risk for atherosclerosis [44]. Increasing HbA1c levels were associated with high Gal3BP levels in women only. To our knowledge, the association between HbA1c and high Gal3BP has not been explored in patients with T1D previously. Smoking and physical inactivity, which are two factors contributing to CVD $[40,41]$, were not associated with Gal3BP in this study, and not with sCD163 and galectin-3 in our previous studies [20, 23]. 
In previous research, increased plasma levels of Gal3BP have been associated with CV and all-cause mortality [8]. It is not clarified whether Gal3BP is just a marker of macrophage activation and increased risk for CVD and mortality or whether Gal3BP directly contributes to CVD and mortality [8]. The effects of increased Gal3BP on CVD and mortality might be mediated by associated metabolic and inflammatory disturbances [8]. If there is a direct impact of Gal3BP on CVD and mortality, our findings of increased Gal3BP levels in women might contribute to the increased prevalence of CAC and CV death observed in women with T1D [3, 4].

In future research, the exploration of sex differences of Gal3BP in a larger population of patients with T1D is suggested. Another subject for exploration is the impact of sex hormones on Gal3BP. High Gal3BP levels indicate increased risk for $\mathrm{CV}$ and all-cause mortality according to previous research [8]. Comparing Gal3BP to other metabolic and inflammatory risk factors will be necessary in prospective studies, to evaluate whether Gal3BP is an independent risk factor for CV disease and mortality. We are therefore planning an 11-year follow-up of this study. Whether high Gal3BP levels can be a target for treatment is also a subject for further research.

\section{Conclusions}

Female sex, sCD163, and total cholesterol were positively associated, and HDL-cholesterol was negatively associated with high Gal3BP in patients with T1D. The prevalence of high Gal3BP was more than twice as high in the women as in the men.

\section{Perspectives and significance}

The increased prevalence of high Gal3BP demonstrated in the women might contribute to the increased risk for $\mathrm{CAC}$ and $\mathrm{CV}$ death previously demonstrated in women with T1D. The effects of high Gal3BP on CV disease might be direct, alternately, might be mediated by associated metabolic and inflammatory disturbances. This has to be further explored in longitudinal studies. Potentially, after further research, high Gal3BP might be used either as a valuable risk marker or as a treatment target.

\begin{abstract}
Acknowledgements
The authors are grateful to Anna Lindgren, PhD, at the Department of Mathematical Statistics, Lund University, Lund, Sweden, for her statistical skills. The authors are also grateful to all physicians and nurses that were involved in the recruitment of the participants.
\end{abstract}

\section{Authors' contributions}

EOM, JD, and $\mathrm{MH}$ participated as investigators and reviewed, edited, and approved the manuscript. All authors contributed to the study design, implementation, and analysis. EOM was the initiator of this study, wrote the statistical methods and the manuscript, and is the guarantor of this work and, as such, had full access to all the data in the study and takes responsibility for the integrity of the data and the accuracy of the data analysis. JD and $\mathrm{MH}$ were responsible for the selection of included inflammatory markers and performed and validated the ELISA analyses.

\section{Authors' information}

EOM has a PhD, a medical doctor, and a specialist in Paediatrics and Family Medicine. EOM works at the Department of Research and Development, Region Kronoberg, Växjö, and is affiliated to the Diabetes Research Laboratory, Lund University, Lund. JD has a PhD and works at the Diabetes Research Laboratory, Lund University, Lund. MH has a PhD, an associate professor, and works at the Diabetes Research Laboratory, Lund University, Lund. All Sweden.

\section{Funding}

This research was supported by the Research and Development Fund of Region Kronoberg, Växjö, Sweden, and by the Research Council of South Eastern Sweden (FORSS), Linköping, Sweden. The funding sources were not involved in the collection, analysis, and interpretation of data, in the writing of the report, or in the decision to submit the article for publication.

\section{Availability of data and materials}

All data are saved at SPSS files for 15 years at the Department of Research and Development, Region Kronoberg, Växjö, Sweden. The data sets are not available publicly as individual privacy could be compromised. The data set is available from the corresponding author on reasonable request.

\section{Ethics approval and consent to participate}

The study was approved by the Regional Ethical Review Board of Linköping University, Linköping (Registration no. M120-07, T89-08). All participants provided written informed consent.

\section{Consent for publication}

Not applicable.

\section{Competing interests}

The authors declare that they have no competing interests.

Received: 26 August 2019 Accepted: 25 October 2019

Published online: 21 November 2019

\section{References}

1. Katsarou A, Gudbjörnsdottir S, Rawshani A, Dabelea D, Bonifacio E, Anderson BJ, et al. Type 1 diabetes mellitus. Nat Rev Dis Primer. 2017;3: 17016. https://doi.org/10.1038/nrdp.2017.16.

2. Larsson SC, Wallin A, Håkansson N, Stackelberg O, Bäck M, Wolk A. Type 1 and type 2 diabetes mellitus and incidence of seven cardiovascular diseases. Int J Cardiol. 2018;262:66-70. https://doi.org/10. 1016/ijcard2018.03.099.

3. Colhoun HM, Rubens MB, Underwood SR, Fuller JH. The effect of type 1 diabetes mellitus on the gender difference in coronary artery calcification. J Am Coll Cardiol. 2000;36(7):2160-7. https://doi.org/10.1016/S07351097(00)00986-4.

4. Lind M, Svensson A-M, Kosiborod M, Gudbjörnsdottir S, Pivodic A, Wedel H, et al. Glycemic control and excess mortality in type 1 diabetes. N Engl J Med. 2014;371:1972-82. https://doi.org/10.1056/NEJMoa1408214.

5. Shaked I, Hanna DB, Gleißner C, Marsh B, Plants J, Tracy D, et al. Macrophage inflammatory markers are associated with subclinical carotid artery disease in women with human immunodeficiency virus or hepatitis C virus infection. Arterioscler Thromb Vasc Biol. 2014;34:1085-92. https://doi. org/10.1161/ATVBAHA.113.303153.

6. Koths K, Taylor E, Halenbeck R, Casipit C, Wang A. Cloning and characterization of a human Mac-2-binding protein, a new member of the superfamily defined by the macrophage scavenger receptor cysteine-rich domain. J Biol Chem. 1993;268:14245-9.

7. Grassadonia A, Tinari N, lurisci I, Piccolo E, Cumashi A, Innominato P, et al. 90K (Mac-2 BP) and galectins in tumor progression and metastasis. Glycoconj J. 2002;19:551-6.

8. Gleissner CA, Erbel C, Linden F, Domschke G, Akhavanpoor M, Helmes CM, et al. Galectin-3 binding protein, coronary artery disease and cardiovascular mortality: insights from the LURIC study. Atherosclerosis. 2017;260:121-9. https://doi.org/10.1016/j.atherosclerosis.2017.03.031.

9. Henderson NC, Sethi T. The regulation of inflammation by galectin-3. Immunol Rev. 2009;230:160-71. 
10. Ho JE, Liu C, Lyass A, Courchesne P, Pencina MJ, Vasan RS, et al. Galectin-3, a marker of cardiac fibrosis, predicts incident heart failure in the community. J Am Coll Cardiol. 2012;60:1249-56.

11. Sharma UC, Pokharel S, van Brakel TJ, van Berlo JH, Cleutjens JP, Schroen B, et al. Galectin-3 marks activated macrophages in failure-prone hypertrophied hearts and contributes to cardiac dysfunction. Circulation. 2004;110:3121-8. https://doi.org/10.1161/01.CIR.0000147181.65298.4D.

12. Kusaka H, Yamamoto E, Hirata Y, Fujisue K, Tokitsu T, Sugamura K, et al. Clinical significance of plasma galectin-3 in patients with coronary artery disease. Int J Cardiol. 2015;201:532-4.

13. Tan KC, Cheung C, Lee AC, Lam JK, Wong Y, Shiu SW. Galectin-3 and risk of cardiovascular events and all-cause mortality in type 2 diabetes. Diabetes Metab Res Rev. 2019;35:3093.

14. Kristiansen M, Graversen JH, Jacobsen C, Sonne O, Hoffman H-J, Law SA, et al. Identification of the haemoglobin scavenger receptor. Nature. 2001; 409:198-201. https://doi.org/10.1038/35051594.

15. Møller HJ. Soluble CD163. Scand J Clin Lab Invest. 2012;72:1-13. https://doi. org/10.3109/00365513.2011.626868.

16. Ilter A, Orem C, Yucesan FB, Sahin M, Hosoglu Y, Kurumahmutoglu E, et al. Evaluation of serum sTWEAK and SCD163 levels in patients with acute and chronic coronary artery disease. Int J Clin Exp Med. 2015;8:9394.

17. Parkner T, Sørensen L, Nielsen A, Fischer C, Bibby BM, Nielsen S, et al. Soluble CD163: a biomarker linking macrophages and insulin resistance. Diabetologia. 2012;55:1856-62. https://doi.org/10.1007/s00125-012-2533-1.

18. Fjeldborg K, Christiansen T, Bennetzen M, Møller JH, Pedersen SB, Richelsen B. The macrophage-specific serum marker, soluble CD163, is increased in obesity and reduced after dietary-induced weight loss. Obesity. 2013;21: 2437-43. https://doi.org/10.1002/oby.20376.

19. Al-Daghri NM, Al-Attas OS, Bindahman LS, Alokail MS, Alkharfy KM, Draz HM, et al. Soluble CD163 is associated with body mass index and blood pressure in hypertensive obese Saudi patients. Eur J Clin Investig. 2012;42:1221-6. https://doi.org/10.1111/j.1365-2362.2012.02714.x.

20. Melin EO, Dereke J, Thunander M, Hillman M. Soluble CD163 was linked to galectin-3, diabetic retinopathy and antidepressants in type 1 diabetes. Endocr Connect. 2018;1 https://doi.org/10.1530/EC-18-0336.

21. Raison $\mathrm{CL}$, Capuron L, Miller AH. Cytokines sing the blues: inflammation and the pathogenesis of depression. Trends Immunol. 2006;27:24-31. https://doi. org/10.1016/j.it.2005.11.006

22. Egede LE, Nietert PJ, Zheng D. Depression and all-cause and coronary heart disease mortality among adults with and without diabetes. Diabetes Care 2005;28:1339-45. https://doi.org/10.2337/diacare.28.6.1339.

23. Melin EO, Dereke J, Thunander M, Hillman M. Depression in type 1 diabetes was associated with high levels of circulating galectin-3. Endocr Connect. 2018;7:819-28. https://doi.org/10.1530/EC-18-0108.

24. Melin EO, Thunander M, Svensson R, Landin-Olsson M, Thulesius HO Depression, obesity and smoking were independently associated with inadequate glycemic control in patients with type 1 diabetes. Eur J Endocrinol. 2013;168:861-9. https://doi.org/10.1530/eje-13-0137.

25. Melin EO, Thunander M, Landin-Olsson M, Hillman M, Thulesius HO. Depression, smoking, physical inactivity and season independently associated with midnight salivary cortisol in type 1 diabetes. BMC Endocr Disord. 2014;14:75. https://doi.org/10.1186/1472-6823-14-75.

26. Melin EO, Thulesius HO, Hillman M, Svensson R, Landin-Olsson M, Thunander M. Lower HDL-cholesterol, a known marker of cardiovascular risk, was associated with depression in type 1 diabetes: a cross sectional study. Lipids Health Dis. 2019;18:65. https://doi.org/10.1186/s12944-019-1009-4.

27. Purnell JQ, Hokanson JE, Cleary PA, Nathan DM, Lachin JM, Zinman B, et al. The effect of excess weight gain with intensive diabetes treatment on cardiovascular disease risk factors and atherosclerosis in type 1 diabetes: results from the Diabetes Control and Complications Trial / Epidemiology of Diabetes Interventions and Complications Study (DCCT/EDIC) study. Circulation. 2013; 127:180-7. https://doi.org/10.1161/CIRCULATIONAHA.111.077487.

28. Melin EO, Thulesius HO, Hillman M, Landin-Olsson M, Thunander M. Abdominal obesity in type 1 diabetes associated with gender, cardiovascular risk factors and complications, and difficulties achieving treatment targets: a cross sectional study at a secondary care diabetes clinic. BMC Obes. 2018;5:15. https://doi.org/10.1186/s40608-018-0193-5.

29. Melin EO, Svensson R, Thunander M, Hillman M, Thulesius HO, Landin-Olsson M. Gender, alexithymia and physical inactivity associated with abdominal obesity in type 1 diabetes mellitus: a cross sectional study at a secondary care hospital diabetes clinic. BMC Obes. 2017;4:21. https://doi.org/10.1186/s40608-017-0157-1.
30. Dereke J, Nilsson J, Nilsson C, Strevens H, Landin-Olsson M, Hillman M Soluble CD163 and TWEAK in early pregnancy gestational diabetes and later glucose intolerance. PLoS One. 2019;14:0216728. https://doi.org/10. 1371/journal.pone.0216728.

31. Lasnier E, Mario N, Boque M-C, You S-N, Vaubourdolle M. Evaluation of the clinical chemistry analyser Olympus AU400. Clin Chem Lab Med. 2000;38: 1043-9. https://doi.org/10.1515/CCLM.2000.155.

32. Ridker PM. LDL cholesterol: controversies and future therapeutic directions. Lancet. 2014;384:607-17. https://doi.org/10.1016/S0140-6736(14)61009-6.

33. Klein S, Allison DB, Heymsfield SB, Kelley DE, Leibel RL, Nonas C, et al. Waist circumference and cardiometabolic risk: a consensus statement from Shaping America's Health: Association for Weight Management and Obesity Prevention; NAASO, The Obesity Society; the American Society for Nutrition; and the American Diabetes Association. Obesity. 2007;15:1061-7. https://doi. org/10.1038/oby.2007.632

34. Zigmond AS, Snaith RP. The hospital anxiety and depression scale. Acta Psychiatr Scand. 1983;67:361-70. https://doi.org/10.1111/j.1600-0447.1983. tb09716.x.

35. The National Board of Health and Welfare. Swedish National Guidelines for Diabetes. 2009

36. Kato S, Chmielewski M, Honda H, Pecoits-Filho R, Matsuo S, Yuzawa Y, et al. Aspects of immune dysfunction in end-stage renal disease. Clin J Am Soc Nephrol. 2008;3:1526-33. https://doi.org/10.2215/CJN.00950208.

37. Correale M, Giannuzzi V, lacovazzi P, Valenza M, Lanzillotta S, Abbate I, et al. Serum 90K/MAC-2BP glycoprotein levels in hepatocellular carcinoma and cirrhosis. Anticancer Res. 1999:19:3469-72.

38. Giansanti F, Capone E, Ponziani S, Piccolo E, Gentile R, Lamolinara A, et al. Secreted Gal-3BP is a novel promising target for non-internalizing antibodydrug conjugates. J Control Release. 2019;294:176-84.

39. American Diabetes Association. 9. Cardiovascular disease and risk management: standards of medical care in diabetes_2018. Diabetes Care. 2018:41:S86-104.

40. Messner B, Bernhard D. Smoking and cardiovascular disease: mechanisms of endothelial dysfunction and early atherogenesis. Arterioscler Thromb Vasc Biol. 2014:34:509-15.

41. Lee I-M, Shiroma EJ, Lobelo F, Puska P, Blair SN, Katzmarzyk PT, et al. Effect of physical inactivity on major non-communicable diseases worldwide: an analysis of burden of disease and life expectancy. Lancet. 2012;380:219-29. https://doi.org/10.1016/S0140-6736(12)61031-9.

42. Purnamawati K, Ong JA-H, Deshpande S, Tan WK-Y, Masurkar N, Low JK, et al. The importance of sex stratification in autoimmune disease biomarker research: a systematic review. Front Immunol. 2018;9 https://doi.org/10. 3389/fimmu.2018.01208

43. Grassadonia A, Tinari N, Fiorentino B, Suzuki K, Nakazato M, De Tursi M, et al. The $90 \mathrm{~K}$ protein increases major histocompatibility complex class I expression and is regulated by hormones, $y$-interferon, and double-strand polynucleotides. Endocrinology. 2004;145:4728-36.

44. Rosenson RS, Brewer HB Jr, Ansell BJ, Barter P, Chapman MJ, Heinecke JW, et al. Dysfunctional HDL and atherosclerotic cardiovascular disease. Nat Rev Cardiol. 2016:13:48.

\section{Publisher's Note}

Springer Nature remains neutral with regard to jurisdictional claims in published maps and institutional affiliations.

Ready to submit your research? Choose BMC and benefit from

- fast, convenient online submission

- thorough peer review by experienced researchers in your field

- rapid publication on acceptance

- support for research data, including large and complex data types

- gold Open Access which fosters wider collaboration and increased citations

- maximum visibility for your research: over $100 \mathrm{M}$ website views per year

At $\mathrm{BMC}$, research is always in progress.

Learn more biomedcentral.com/submission 